Supplement of Adv. Geosci., 45, 201-208, 2018

https://doi.org/10.5194/adgeo-45-201-2018-supplement

(C) Author(s) 2018. This work is distributed under

the Creative Commons Attribution 4.0 License.

(c) (1)

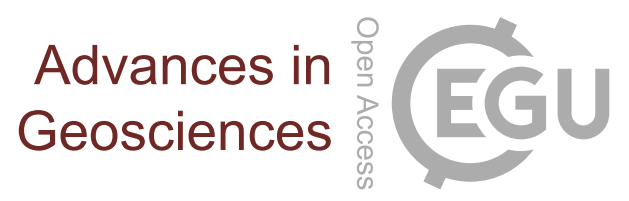

Supplement of

\title{
Evaluation of random forests and Prophet for daily streamflow forecasting
}

Georgia A. Papacharalampous and Hristos Tyralis

Correspondence to: Georgia A. Papacharalampous (papacharalampous.georgia@gmail.com)

The copyright of individual parts of the supplement might differ from the CC BY 4.0 License. 

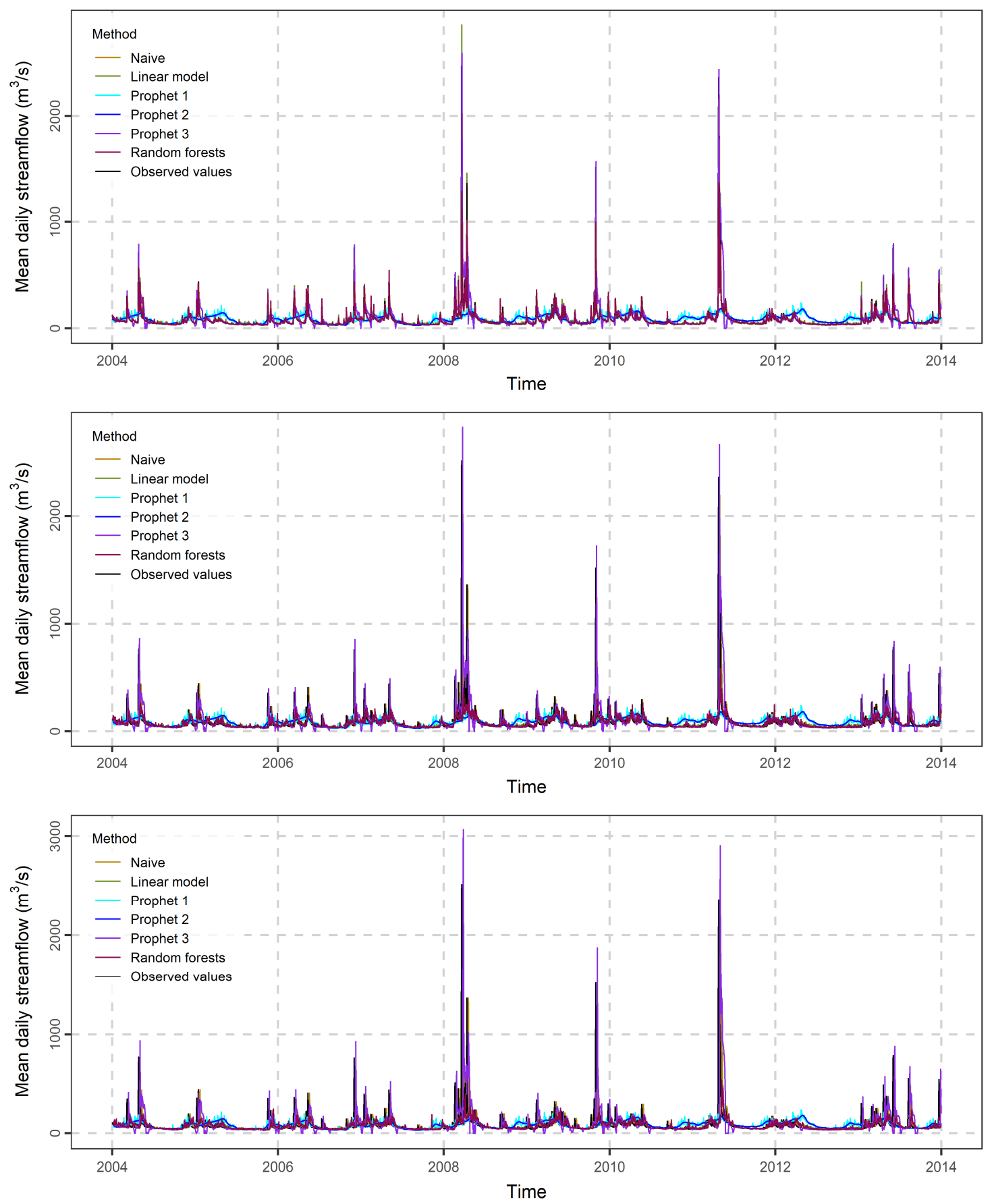

Figure S.1. 1-, 4- and 7-step ahead forecasts (from top to bottom) of the Current river daily streamflow in the period 2004-2013. 

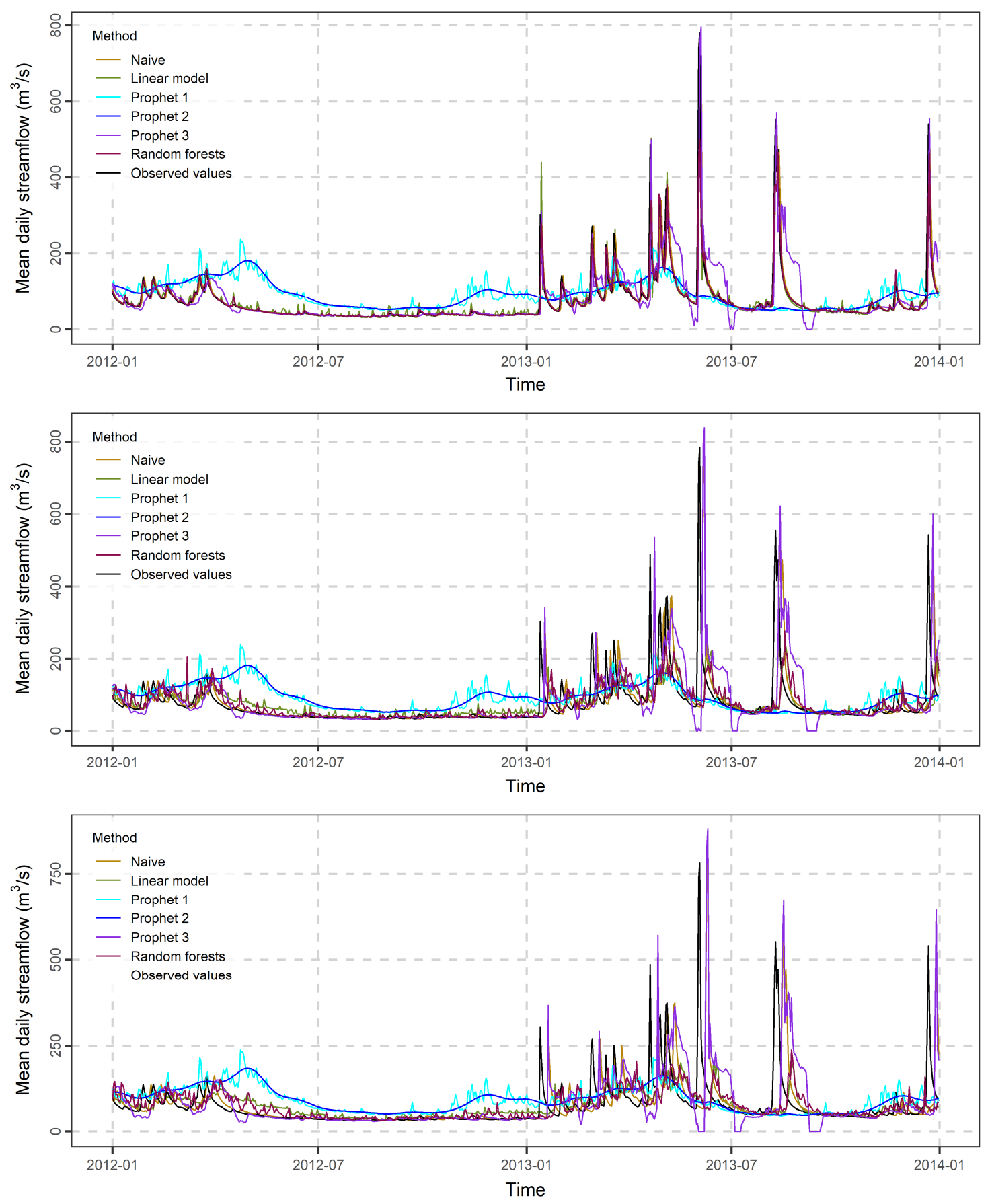

Figure S.2. 1-, 4- and 7-step ahead forecasts (from top to bottom) of the Current river daily streamflow in the period 2012-2013. 